\title{
Binding Energies of Water to Lithiated Valine: Formation of Solution-Phase Structure in vacuo
}

\author{
Andrew S. Lemoff and Evan R. Williams \\ Department of Chemistry, University of California at Berkeley, Berkeley, California, USA
}

\begin{abstract}
Dissociation kinetics for loss of a water molecule from hydrated ions of lithiated valine, alanine ethyl ester and betaine are determined using blackbody infrared radiative dissociation at temperatures between -60 and $110{ }^{\circ} \mathrm{C}$. From master equation modeling of these data, values of the threshold dissociation energy are obtained for clusters containing one through three water molecules. By comparing the values for valine with its two isomers, one a model for the nonzwitterion structure, the other a model for the zwitterion structure, information about the structure of valine in these hydrated clusters is inferred. Structures, relative energies, and water binding energies for these ions are also calculated at the B3LYP/6-31 $++\mathrm{G}^{* *}$ level of theory. With one water molecule, both experiment and theory indicate that valine is not a zwitterion and that the lithium ion coordinates with the amino nitrogen and the carbonyl oxygen (NO coordinated) and the water molecule interacts directly with the lithium ion. With two water molecules, the zwitterion and nonzwitterion structures are nearly isoenergetic, but the experiment clearly indicates a NO-coordinated nonzwitterion structure. With three water molecules, both the experimental data and theory indicate that the lithium ion binds to the carboxylate group of valine, i.e., valine is zwitterionic with three water molecules. The agreement between the experimentally determined and calculated binding energies is good for all the clusters, with deviations of $\leq 0.12 \mathrm{eV}$. (J Am Soc Mass Spectrom 2004, 15, 1014-1024) (C) 2004 American Society for Mass Spectrometry
\end{abstract}

$\mathrm{M}$ olecular structure in solution depends on both the intrinsic properties of the molecule and on the effects of the surrounding solvent molecules. Exclusion of water from the interior of proteins influences protein folding and conformation. Similarly, lipid bilayer formation is due to differences in water interaction with the polar and hydrophobic ends of the lipid molecules. Gas-phase experiments make possible investigation of the intrinsic properties of the molecule. Differences between gas-phase and solution-phase structure can be attributed to solvent effects. Studies of gas-phase peptides indicate that $\alpha$-helices can be stable in the absence of water and indicate that the propensity for helix formation for some amino acids differs in the gas phase and in solution [1, 2]. For example, peptides with high valine content have a higher helix-forming propensity than their alanine analogues in the gas phase, but just the opposite is observed in aqueous solution [1].

In the condensed phase, specific water molecules can

Published online June 8, 2004

Address reprint requests to Professor E. R. Williams, Department of Chemistry, University of California, Berkeley, CA 94720-1460, USA. E-mail: williams@cchem.berkeley.edu play an important role in molecular structure. Such specific water molecules are often observed in crystal structures of proteins and other molecules. Evidence for specific water has been reported by Jarrold and coworkers for the molecule BPTI which tightly binds one water molecule in the gas phase [3,4]. Magic hydration numbers for gramicidin $S$ at 8,11 , and 14 water molecules suggest stable solvation shells around the doubly protonated gas-phase ion [5], while a magic hydration number of 40 water molecules has been attributed to two pentagonal dodecahedron clathrate structures surrounding the two protonated ornithine groups [6]. Greater extents of hydration observed for gramicidin S than for cyclosporine A, two peptides of similar size, have been related to the greater hydrophilicity of the former [7]. Absorption of water on globular proteins occurs more readily than on helical ones [2]. From measurements of hydration free energies, information about peptide structures can be inferred [8-11]. Such hydration studies provide useful insight into effects of water on molecular structure and how water molecules interact with biomolecules [12-16].

Water plays a key role in moderating electrostatic interactions in charged molecules. Amino acids are zwitterionic in aqueous solution over a wide $\mathrm{pH}$ range, 
but their nonzwitterion form is more stable in the absence of solvent. The nonzwitterion form of glycine is $\sim 20 \mathrm{kcal} / \mathrm{mol}$ more stable than the zwitterion form in the gas phase [17]. For arginine, the most basic amino acid, the two forms are more comparable in energy [18], but the nonzwitterion is $\sim 3 \mathrm{kcal} / \mathrm{mol}$ more stable [18-22]. The zwitterion form can be made more stable by attaching a metal ion or an electron to it. Calculations indicate that an attached alkali metal cation [23-27], silver (I) ion [28], or zinc (I) ion [29] can lower the relative energy of the zwitterion or salt-bridge form of glycine to only $1-4 \mathrm{kcal} / \mathrm{mol}$ higher in energy than the nonzwitterion or charge-solvated form of these ions. Experimental evidence indicates that only the chargesolvated form exists in the gas phase [26, 30]. For $\mathrm{Gly} \cdot \mathrm{Ni}^{+}$and $\mathrm{Gly} \cdot \mathrm{Cu}^{+}$, the nonzwitterion forms are $\sim 14$ and $10 \mathrm{kcal} / \mathrm{mol}$ more stable, respectively [31, 32]. Attachment of divalent alkaline earth metal ions (except $\mathrm{Be}^{2+}$ ) [33], $\mathrm{Cu}^{2+}$ [32] and $\mathrm{Zn}^{2+}$ [29] can make the zwitterion or salt-bridge form of glycine more stable by 5-12 kcal/mol.

For arginine, evidence suggests a nonzwitterion or charge-solvated form when $\mathrm{Li}^{+}$or $\mathrm{Na}^{+}$is attached, but a zwitterion or salt-bridge form with $\mathrm{K}^{+}, \mathrm{Rb}^{+}$, and $\mathrm{Cs}^{+}$ $[30,34]$. Attachment of an electron is sufficient to make the zwitterion form slightly more stable [23, 35]. The stability of higher order clusters of both neutral and charged arginine has been attributed to zwitterionic arginine [18, 36-38]. Protonated octamers of serine are unusually stable in the gas phase [39-41] and a structure in which all the serine molecules are zwitterionic has been proposed [39, 40].

For proline, attachment of an alkali metal or $\mathrm{Ag}^{+}$ cation can make the zwitterion or salt-bridge form more stable than the nonzwitterion or charge-solvated form by $2-7 \mathrm{kcal} / \mathrm{mol}[30,42,43]$, but for $\mathrm{Cu}^{+}$, the chargesolvated form is $3.4 \mathrm{kcal} / \mathrm{mol}$ more stable $[32,44]$. The higher propensity for arginine and proline to form zwitterion or salt-bridge structures is due in part to the higher gas-phase proton affinity of the proton acceptor and the poor charge-solvating ability in the case of proline. These and other factors influencing the intrinsic propensity of zwitterion formation are described elsewhere [26, 45-47].

The effects of water on amino acid structure have been investigated using theory [48-52], spectroscopy [52-55], and by blackbody infrared radiative dissociation (BIRD) $[45,56,57]$. Calculations indicate that two water molecules can make the zwitterion form of glycine a local minimum on the potential energy surface, but this structure is still $\sim 12 \mathrm{kcal} / \mathrm{mol}$ higher in energy than the nonzwitterion [48]. Theory suggests that three water molecules can make the two forms of glycine nearly degenerate in energy [17]. Results from calculations on aspartic acid with three water molecules indicate that the zwitterion form is more stable [58].

Spectroscopic investigations of tryptophan water clusters generated in a free jet expansion by Peteanu and Levy indicated that the water molecule binds to the amino group of the tryptophan side chain [59]. Timeof-flight mass spectra of laser evaporated tryptophan measured by Simons and coworkers show the presence of an unusually stable $\operatorname{Trp}\left(\mathrm{H}_{2} \mathrm{O}\right)_{3}$ cluster which is suggested to be zwitterionic [54]. Recent photoelectron spectroscopy results of Bowen and coworkers indicate that four water molecules transform the dipole bound anion of both phenylalanine and tryptophan to their zwitterion form [55]. Five water molecules were found to be necessary for glycine [55].

The structure of cationized valine with different numbers of water molecules attached has been investigated using a combination of BIRD experiments and theory $[56,57]$. Kinetic data for the loss of a water molecule from cationized valine, $\mathrm{Val} \cdot \mathrm{M}^{+}\left(\mathrm{H}_{2} \mathrm{O}\right)_{n}, \mathrm{M}=$ $\mathrm{Li}, \mathrm{Na}, \mathrm{K}$, and related isomers that model the nonzwitterion and zwitterion forms of valine were measured. These data indicate that the metal binds to the carbonyl oxygen and the amino nitrogen of the nonzwitterion form ( $\mathrm{NO}$ coordination) for $\mathrm{Li}$ and $\mathrm{Na}$, but for $\mathrm{K}$, the metal binds to the two oxygen atoms (OO coordination). The data indicated that attachment of a water molecule to the clusters with either $\mathrm{Li}$ or $\mathrm{Na}$ does not significantly affect the structures or the relative energetics of these ions [56]. With two water molecules, the experiments clearly indicated that the mode of metal ion binding to valine remains the same for Li clusters, but the mode of metal ion binding changes to $\mathrm{OO}$ coordination for the $\mathrm{Na}$ clusters. With three water molecules, the kinetics data strongly indicate that valine is zwitterionic in the clusters with $\mathrm{Li}$, and that the metal is OO coordinated. For both $\mathrm{Li}$ and $\mathrm{Na}$, clusters with six water molecules are more stable than clusters with five water molecules, indicating an unusually stable arrangement of water consistent with valine being zwitterionic in these clusters [57].

Here, the threshold dissociation energies of water from $\mathrm{Val} \cdot \mathrm{Li}^{+}\left(\mathrm{H}_{2} \mathrm{O}\right)_{n}, n=1-3$ and two isomeric model compounds are determined using BIRD. We show that the binding energy of water to the zwitterion and nonzwitterion reference structures differ and that this difference in energy can be used as a probe of zwitterionic structure in these clusters. These results provide additional evidence that three water molecules are required to change valine from its preferred nonzwitterion form in the gas phase, to its solution-phase zwitterion form in these clusters.

\section{Experimental}

\section{Chemicals}

Valine (Val) was obtained from Sigma Chemical Co. (Saint Louis, MO). The hydrochloride salt of alanine ethyl ester (AlaOEt), the monohydrate and hydrochloride salt of betaine (Bet), and lithium hydroxide were obtained from Aldrich Chemical Co. (Milwaukee, WI). Lithium chloride was purchased from Fisher Scientific (Fair Lawn, NJ). All chemicals were used as purchased. 
Electrospray solutions were made to $1.0 \mathrm{mM}$ amino acid (or amino acid analogue) and $1.0 \mathrm{mM}$ metal ion using deionized water. Chloride salts were used to form hydrated $\mathrm{Val} \cdot \mathrm{M}^{+}$and Bet $\cdot \mathrm{M}^{+}$clusters while metal hydroxides gave much better signals for the AlaOEt $\cdot \mathrm{M}^{+}$ clusters. Separate experiments comparing the evaporation rates of water from Bet $\cdot \mathrm{M}^{+}$clusters made with metal hydroxide and metal chloride salts were performed. No differences in evaporation rates were observed, indicating that the source of the metal ion and the presence of chloride versus hydroxide in the electrospray solution do not affect the dissociation kinetics of the isolated ions.

\section{Mass Spectrometry}

Ions are formed by nanoelectrospray ionization using $0.78 \mathrm{~mm}$ inner diameter borosilicate capillaries that are pulled to a diameter of $\sim 3-5 \mu \mathrm{m}$ using a FlamingBrown micropipette puller (Sutter Instruments model P-87, Novato, CA). A platinum wire inserted down the center of the other end of the capillary is used as an electrode and is held at a potential of $\sim 1 \mathrm{kV}$. The tip of the nanospray capillary is placed approximately $1 \mathrm{~mm}$ from the electrospray interface of the home-built Fourier-transform mass spectrometer that has a $2.7 \mathrm{~T}$ superconducting magnet. Information about our instrument is provided elsewhere $[60,61]$. After a period of 2-6 s, during which electrospray generated ions are accumulated in the ion cell, a mechanical shutter is closed to stop additional ions from entering the cell. Nitrogen gas is pulsed into the ion cell at a pressure of $\sim 2 \times 10^{-6}$ torr during the ion accumulation period to assist in ion trapping and thermalization. The unwanted ions are ejected from the cell using a series of stored waveform inverse Fourier-transform (SWIFT) and chirp excitation waveforms. The hydrated ion cluster of interest is then allowed to undergo unimolecular dissociation for times ranging from 0-300 s. For experiments involving a heated cell, the temperature of the entire vacuum chamber is raised by using electrically resistive heating blankets located on the outside of the chamber. For experiments done below room temperature, the copper jacket surrounding the cell is cooled to a uniform temperature [61]. This is done by regulating the opening and shutting of a solenoid that controls the flow of liquid nitrogen around the outside of the copper jacket. Prior to all experiments, the temperature is allowed to equilibrate overnight $(>8 \mathrm{~h})$ to ensure that the ions are exposed to a steady state radiative energy distribution from infrared photons emitted from the walls of the copper jacket and vacuum chamber. Following the variable reaction delay, the product ions are excited for detection using a frequency sweep with a rate of $2200 \mathrm{~Hz} / \mu \mathrm{s}$. A detection bandwidth of $4000 \mathrm{kHz}$ is used. Data are acquired using an Odyssey data system (Finnegan MAT, Bremen, Germany). For all clusters of a specific hydration number, the experimental sequence (load time, isolation waveforms) was op- timized to maximize the abundance of Bet $\cdot \mathrm{M}^{+}\left(\mathrm{H}_{2} \mathrm{O}\right)_{n}$. The same experimental sequence was then used for the other isomeric clusters, and these sets of experiments were done on the same day, immediately following each other. This was done in order to ensure that dissociation of the isomeric clusters, i.e., those with the same extent of hydration, was done under as identical experimental conditions as possible. Dissociation measurements are made at cell pressures below $1 \times 10^{-8}$ torr. At this pressure, collisions with background molecules do not affect dissociation rates and the rate constants measured are in the zero-pressure limit [62-65] .

Although the copper jacket is at a known temperature, there are holes in the jacket that make possible the introduction of sample and electrical connections into the ion cell. These openings allow radiation from other parts of the vacuum chamber to enter the ion cell and interact with the ions. The electrical connections conduct heat to the ion cell inside the copper jacket. For these reasons, the internal energy distribution of the ions is not well characterized for the experiments performed in the cooled cell at low temperature. Therefore, we will refer to the temperature of the copper jacket as the nominal temperature of the ion cell. The temperature that the ions experience inside the cooled cell has been calibrated to the temperature of the copper jacket. The procedure by which this is done, and the accuracy of BIRD data at reduced temperatures is reported elsewhere [61].

\section{Computational Details}

Lowest-energy structures of $\mathrm{AA} \cdot \mathrm{Li}^{+}\left(\mathrm{H}_{2} \mathrm{O}\right)_{n}, n=0-3$, have been previously reported at the $\mathrm{B} 3 \mathrm{LYP} / 6-31+\mathrm{G}^{*}$ level of theory $[56,57]$. These structures were used as starting structures for higher level calculations (B3LYP/ $\left.6-31++G^{* *}\right)$ for this study. Hybrid method density functional calculations (B3LYP) were performed using Jaguar version 4.1 (Schrödinger, Inc., Portland, OR).

Water binding energies were calculated from these lowest-energy structures. The $0 \mathrm{~K}$ energy of the $\mathrm{AA} \cdot \mathrm{Li}^{+}\left(\mathrm{H}_{2} \mathrm{O}\right)_{n}$ complex, which includes both electronic energies and nuclear repulsion, is subtracted from the sum of the $0 \mathrm{~K}$ energies of $\mathrm{H}_{2} \mathrm{O}$ and the lowest-energy $\mathrm{AA} \cdot \mathrm{Li}^{+}\left(\mathrm{H}_{2} \mathrm{O}\right)_{n-1}$ complex. This yields adiabatic binding energies. For the $\mathrm{Val} \cdot \mathrm{Li}^{+}\left(\mathrm{H}_{2} \mathrm{O}\right)_{n}$ zwitterion, $n=1$ and 2, $\mathrm{Val} \cdot \mathrm{Li}^{+}\left(\mathrm{H}_{2} \mathrm{O}\right)_{3}$ nonzwitterion, and $\mathrm{Bet} \cdot \mathrm{Li}^{+}\left(\mathrm{H}_{2} \mathrm{O}\right)_{2}$, nonadiabatic binding energies were calculated by using the lowest energy $\mathrm{AA} \cdot \mathrm{Li}^{+}\left(\mathrm{H}_{2} \mathrm{O}\right)_{n-1}$ complex that has the same modes of metal ion and water binding as the $\mathrm{AA} \cdot \mathrm{Li}^{+}\left(\mathrm{H}_{2} \mathrm{O}\right)_{n}$ complex. For these complexes, it is likely that the dissociative transition state will share the same metal ion and water binding modes as the lowestenergy reactant ion and hence should provide binding energies that are more comparable to the experimentally derived values than the adiabatic binding energy.

In the BIRD experiments, the measured rate for the loss of a water molecule is dependent on the radiative absorption and emission rates, the transition state en- 
<smiles>CCOC(=O)C(C)N</smiles>

Scheme 1

tropy of the dissociation, and the binding energy of the water to the ion. We can numerically simulate the experiment by modeling these processes using a master equation formalism. This is discussed in detail elsewhere $[45,64]$. The error bars reported are a measure of the reproducibility of the experimentally derived values of $E_{0}$. These do not reflect systematic errors that may be present, particularly for values measured at low temperatures. However, a recent comparison of water binding energies to $\mathrm{Ca}^{2+}$ and $\mathrm{Mg}^{2+}$ measured by BIRD at low temperatures to high-pressure equilibrium measurements indicate that any systematic deviations that may be present are very small [61].

\section{Results and Discussion}

The structures of $\mathrm{Val} \cdot \mathrm{Li}^{+}\left(\mathrm{H}_{2} \mathrm{O}\right)_{n}, n=1-3$, were investigated using both blackbody infrared radiative dissociation (BIRD) experiments and theory. In these experiments, structural information, i.e., zwitterion versus nonzwitterion, is deduced by comparing kinetic data, measured over a wide temperature range, for the loss of a water molecule from the ion of interest to that for model isomeric compounds of known structure. Betaine is used as a model of the zwitterionic form of valine, while alanine ethyl ester is a model of the nonzwitterionic forms of valine. Both isomers have been shown previously to be good model compounds, having similar metal ion and water binding interactions and comparable integrated infrared absorption cross-sections [56]. The structures of these molecules are shown in Scheme 1. These three molecules are referred to as AAs (amino acid or amino acid analogue).

BIRD rate constants for the loss of a single water molecule from $\mathrm{Val} \cdot \mathrm{Li}^{+}\left(\mathrm{H}_{2} \mathrm{O}\right)_{n}, n=1-3$, are measured at copper jacket temperatures between -60 and $110{ }^{\circ} \mathrm{C}$. Rate constants are determined from the slope of $\ln$ $\left\{\left[\mathrm{AA} \cdot \mathrm{Li}^{+}\left(\mathrm{H}_{2} \mathrm{O}\right)_{n}\right] /\left(\left[\mathrm{AA} \cdot \mathrm{Li}^{+}\left(\mathrm{H}_{2} \mathrm{O}\right)_{n}\right]+\left[\mathrm{AA} \cdot \mathrm{Li}^{+}\left(\mathrm{H}_{2} \mathrm{O}\right)_{n-1}\right]\right.\right.$ $\left.\left.+\ldots+\left[\mathrm{AA}^{2} \cdot \mathrm{Li}^{+}\right]\right)\right\}$versus time, where $\left[\mathrm{AA} \cdot \mathrm{Li}^{+}\left(\mathrm{H}_{2} \mathrm{O}\right)_{n}\right]$ represents the ion abundance of a cluster with $\mathrm{n}$ water molecules. All the data can be fit well by straight lines with correlation coefficients $\geq 0.99$, indicating first-order kinetics.
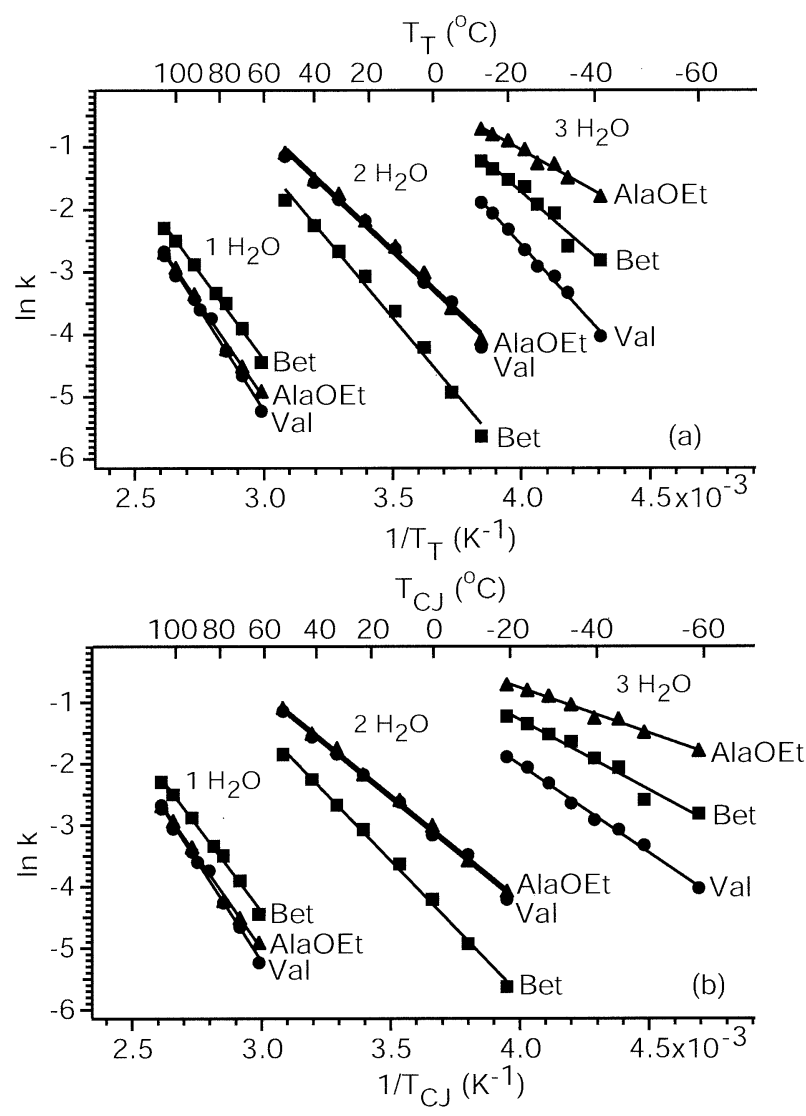

Figure 1. Arrhenius plots for the loss of a water molecule from $\mathrm{AA} \cdot \mathrm{Li}+\left(\mathrm{H}_{2} \mathrm{O}\right)_{\mathrm{n}}, \mathrm{AA}=\mathrm{Val}$, AlaOEt, Bet and $\mathrm{n}=1-3$, for $(\mathbf{a}) \mathrm{T}_{\mathrm{T}}$ and (b) $\mathrm{T}_{\mathrm{CJ}}$.

Due to holes in the copper jacket surrounding the ion cell and electrical connections which conduct heat to the ion cell inside the copper jacket, the internal energy distribution of the ions is not well characterized for the experiments performed when the cell is significantly below room temperature. Two temperature scales are used for the analysis of the data for the experiments done below room temperature: one which is the temperature of the copper jacket surrounding the cell $\left(\mathrm{T}_{\mathrm{CJ}}\right)$, and a temperature scale which is calibrated to a thermocouple that was placed inside the cell in earlier experiments $\left(\mathrm{T}_{\mathrm{T}}\right)$ [61]. Arrhenius parameters for water binding are determined from plotting the natural logs of the zero-pressure limit water dissociation rate constants as a function of $1 / \mathrm{T}$ using both of these temperature scales. The two temperature scales represent both an upper and a lower limit to the uncertainty in the temperature. Arrhenius plots using both $\mathrm{T}_{\mathrm{T}}$ (top) and $\mathrm{T}_{\mathrm{CJ}}$ (bottom) are shown in Figure 1. Correlation coefficients for all the Arrhenius data are $\geq 0.992$ with $T_{T}$ and $\geq 0.993$ with $\mathrm{T}_{\mathrm{CJ}}$.

$A A \cdot \mathrm{Li}^{+}\left(\mathrm{H}_{2} \mathrm{O}\right)$

The Arrhenius data for the dissociation of water from $\mathrm{AA} \cdot \mathrm{Li}^{+}\left(\mathrm{H}_{2} \mathrm{O}\right)$ were obtained at temperatures between 
Table 1. Zero-pressure limit Arrhenius $E_{a}$ and $\log A$ values for loss of a water molecule from AA $\cdot \mathrm{Li}^{+}\left(\mathrm{H}_{2} \mathrm{O}\right)_{n}, n=1-3$, using $\mathrm{T}_{\mathrm{CI}}$ and $\mathrm{T}_{\mathrm{T}}$

\begin{tabular}{llcccc}
\hline$n$ & AA & $\begin{array}{c}\mathrm{E}_{\mathrm{a}}(\mathrm{eV}) \\
\mathrm{T}_{\mathrm{CJ}}\end{array}$ & $\begin{array}{c}\log \mathrm{A} \\
\mathrm{T}_{\mathrm{CJ}}\end{array}$ & $\begin{array}{c}\mathrm{E}_{\mathrm{a}}(\mathrm{eV}) \\
\mathrm{T}_{\mathrm{T}}\end{array}$ & $\begin{array}{c}\log \mathrm{A} \\
\mathrm{T}_{\mathrm{T}}\end{array}$ \\
\hline \hline 1 & Val & $0.56 \pm 0.01$ & $6.2 \pm 0.2$ & $0.56 \pm 0.01$ & $6.2 \pm 0.2$ \\
& AlaOEt & $0.52 \pm 0.01$ & $5.7 \pm 0.1$ & $0.52 \pm 0.01$ & $5.7 \pm 0.1$ \\
& Bet & $0.48 \pm 0.02$ & $5.4 \pm 0.2$ & $0.48 \pm 0.02$ & $5.4 \pm 0.2$ \\
2 & Val & $0.30 \pm 0.01$ & $4.1 \pm 0.1$ & $0.34 \pm 0.01$ & $4.8 \pm 0.2$ \\
& AlaOEt & $0.30 \pm 0.01$ & $4.2 \pm 0.1$ & $0.34 \pm 0.01$ & $4.8 \pm 0.2$ \\
& Bet & $0.38 \pm 0.01$ & $5.1 \pm 0.2$ & $0.43 \pm 0.02$ & $5.9 \pm 0.3$ \\
3 & Val & $0.24 \pm 0.01$ & $3.9 \pm 0.2$ & $0.39 \pm 0.01$ & $6.8 \pm 0.2$ \\
& AlaOEt & $0.12 \pm 0.01$ & $2.1 \pm 0.1$ & $0.20 \pm 0.01$ & $3.6 \pm 0.2$ \\
& Bet & $0.19 \pm 0.02$ & $3.3 \pm 0.3$ & $0.29 \pm 0.02$ & $5.1 \pm 0.3$ \\
\hline
\end{tabular}

61 and $110{ }^{\circ} \mathrm{C}$ for the three complexes (Figure 1). Because all of these data were obtained above room temperature, $\mathrm{T}_{\mathrm{T}}=\mathrm{T}_{\mathrm{CJ}}$. The values of the rate constants for $\mathrm{Val} \cdot \mathrm{Li}^{+}\left(\mathrm{H}_{2} \mathrm{O}\right)$ and $\mathrm{AlaOEt} \cdot \mathrm{Li}^{+}\left(\mathrm{H}_{2} \mathrm{O}\right)$ are similar to each other, and both are different from those for Bet $\cdot \mathrm{Li}^{+}\left(\mathrm{H}_{2} \mathrm{O}\right)$ over this temperature range (Figure 1 ). The measured zero-pressure Arrhenius activation energies $\left(\mathrm{E}_{\mathrm{a}}\right)$ and pre-exponential factors $(\mathrm{A})$ obtained from the Arrhenius plots are given in Table 1. The $\mathrm{E}_{\mathrm{a}}$ and $\log$ A values for $\mathrm{Val} \cdot \mathrm{Li}^{+}\left(\mathrm{H}_{2} \mathrm{O}\right)$ and $\mathrm{AlaOEt} \cdot \mathrm{Li}^{+}\left(\mathrm{H}_{2} \mathrm{O}\right)$ are within $\sim 7-8 \%$, while the $\mathrm{E}_{\mathrm{a}}$ and $\log \mathrm{A}$ values for $\mathrm{Val} \cdot \mathrm{Li}^{+}\left(\mathrm{H}_{2} \mathrm{O}\right)$ and $\mathrm{Bet} \cdot \mathrm{Li}^{+}\left(\mathrm{H}_{2} \mathrm{O}\right)$ are within $\sim 13-14 \%$. Despite the fact that these values for AlaOEt $\cdot \mathrm{Li}^{+}\left(\mathrm{H}_{2} \mathrm{O}\right)$ are in between those of $\mathrm{Val} \cdot \mathrm{Li}^{+}\left(\mathrm{H}_{2} \mathrm{O}\right)$ and $\mathrm{Bet} \cdot \mathrm{Li}^{+}\left(\mathrm{H}_{2} \mathrm{O}\right)$, the dissociation kinetics for loss of water from the alanine ethyl ester complex are much more similar to those for the valine complex than to those for the betaine complex (Figure 1). This suggests that the mode of water binding in $\mathrm{Val} \cdot \mathrm{Li}^{+}\left(\mathrm{H}_{2} \mathrm{O}\right)$ is likely more similar to that in $\mathrm{AlaOEt} \cdot \mathrm{Li}^{+}\left(\mathrm{H}_{2} \mathrm{O}\right)$ than $\mathrm{Bet} \cdot \mathrm{Li}^{+}\left(\mathrm{H}_{2} \mathrm{O}\right)$.

Lowest-energy structures for $\mathrm{AA} \cdot \mathrm{Li}^{+}$at the B3LYP/ $6-31++G^{* *}$ level of theory are shown in Figure 2 . Nonzwitterionic lithiated valine is $0.12 \mathrm{eV}$ lower in
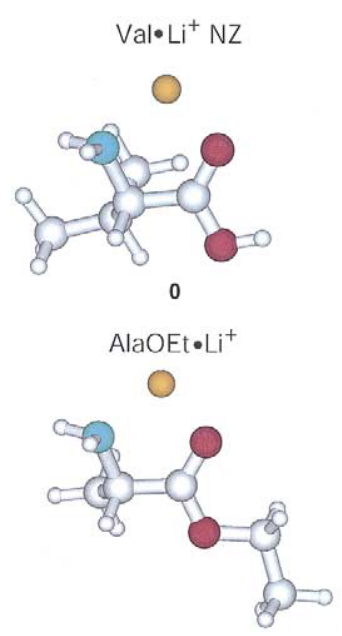

Figure 2. Lowest-energy structures of $\mathrm{AA} \cdot \mathrm{Li}^{+}$complexes at the B3LYP $/ 6-31++\mathrm{G}^{* *}$ level of theory. Relative energies (in $\mathrm{eV}$ ) include corrections for zero-point energy and enthalpy at $298 \mathrm{~K}$.

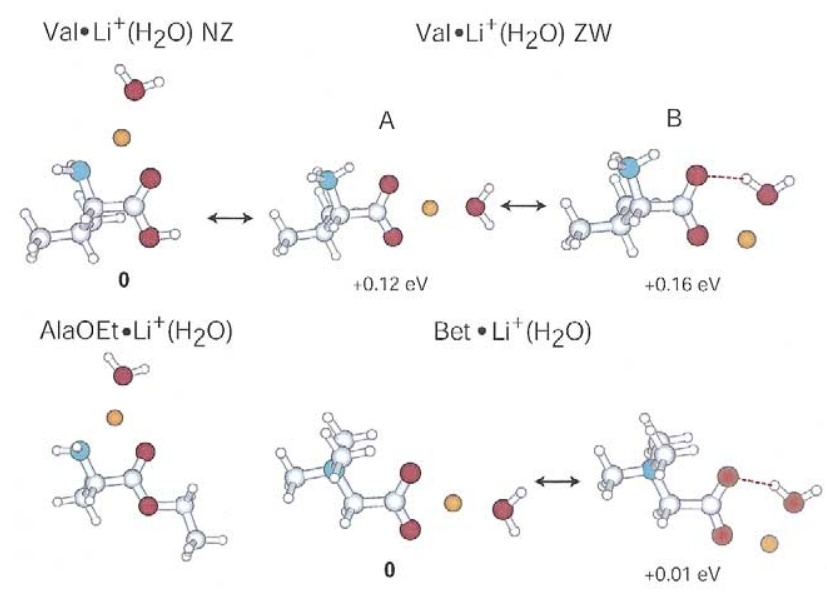

Figure 3. Lowest-energy structures of $\mathrm{AA} \cdot \mathrm{Li}^{+}\left(\mathrm{H}_{2} \mathrm{O}\right)$ complexes at the B3LYP/6-31++ $\mathrm{G}^{* *}$ level of theory. Relative energies (in eV) include corrections for zero-point energy and enthalpy at $298 \mathrm{~K}$.

energy than the zwitterionic form at this level, including zero-point energy and $\Delta \mathrm{H}(298 \mathrm{~K})$ corrections. The metal ion binding in the nonzwitterionic valine complex is modeled well by the alanine ethyl ester complex, with the lithium ion NO-coordinated, while the lithium in zwitterionic valine and betaine complexes is OOcoordinated.

Lowest-energy structures for $\mathrm{AA} \cdot \mathrm{Li}^{+}\left(\mathrm{H}_{2} \mathrm{O}\right)$ at the B3LYP / 6-31 $++\mathrm{G}^{* *}$ level of theory are shown in Figure 3. Nonzwitterionic lithiated valine is $0.12 \mathrm{eV}$ lower in energy than the zwitterion form at this level of theory, including zero-point energy and $\Delta \mathrm{H}(298 \mathrm{~K})$ corrections. The lowest-energy zwitterionic valine structure, A, is slightly different from the previously reported lowestenergy structure at the B3LYP/6-31 $+\mathrm{G}^{*}$ level, B [56]. The energy difference between these structures is relatively small and the barrier for interconversion is also likely to be very small. Thus, the water interaction in both A and B is likely to be comparable. The metal ion and water molecule are bound similarly in the nonzwitterionic valine complex and the alanine ethyl ester complex, while the binding in the zwitterionic valine complexes is similar to that in the betaine complexes.

From master equation modeling of the BIRD data, threshold dissociation energies $\left(\mathrm{E}_{\mathrm{o}}\right)$ for the loss of water from $\mathrm{AA} \cdot \mathrm{Li}^{+}\left(\mathrm{H}_{2} \mathrm{O}\right)$ can be determined. The values are reported in Table 2 . In the modeling, transition dipole moments are calculated and used to determine rates of photon absorption and emission. To take into account uncertainties in these values, modeling is done using transition dipole moment multiplication factors ranging from 0.8 to 1.2. Accurate threshold dissociation energies can be obtained from BIRD experiments using this range of values [65]. Fits to our data cannot be obtained over this entire range. The values of $\mathrm{E}_{\mathrm{o}}$ for $\mathrm{AA} \cdot \mathrm{Li}^{+}\left(\mathrm{H}_{2} \mathrm{O}\right)$ are $0.88 \pm 0.03,0.86 \pm 0.03$, and $0.82 \pm 0.03 \mathrm{eV}$ for AA $=\mathrm{Val}$, AlaOEt, and Bet, respectively. The values of $\mathrm{E}_{\mathrm{o}}$ overlap for $\mathrm{Val} \cdot \mathrm{Li}^{+}\left(\mathrm{H}_{2} \mathrm{O}\right)$ and AlaOEt$\cdot \mathrm{Li}^{+}\left(\mathrm{H}_{2} \mathrm{O}\right)$, while $\mathrm{E}_{\mathrm{o}}$ for $\mathrm{Val} \cdot \mathrm{Li}^{+}\left(\mathrm{H}_{2} \mathrm{O}\right)$ is $\sim 0.06 \mathrm{eV}$ greater than 
Table 2. Threshold dissociaton energies and binding enthalpies (in eV) for loss of a water molecule from $\mathrm{AA} \cdot \mathrm{Li}^{+}\left(\mathrm{H}_{2} \mathrm{O}\right)_{n}, n=1-3$, determined from master equation modeling of the BIRD experiments, using both $\mathrm{T}_{\mathrm{CJ}}$ and $\mathrm{T}_{\mathrm{T}}$, and with transition dipole moment $(\mu)$ multiplication factors ranging from 0.8 to 1.2

\begin{tabular}{|c|c|c|c|c|c|c|}
\hline \multirow{2}{*}{$\frac{\mathrm{AA} \cdot \mathrm{Li}^{+}\left(\mathrm{H}_{2} \mathrm{O}\right)_{n}}{n}$} & \multirow[t]{2}{*}{ AA } & \multicolumn{3}{|c|}{$\mu$} & \multirow[b]{2}{*}{$E_{o}$} & \multirow[b]{2}{*}{$\Delta \mathrm{H}(298 \mathrm{~K})$} \\
\hline & & 0.8 & 1.0 & 1.2 & & \\
\hline \multirow[t]{3}{*}{1} & Val & $0.90-0.91$ & $0.85-0.91$ & $0.85-0.91$ & $0.85-0.91$ & $0.87-0.93$ \\
\hline & AlaOEt & $0.87-0.88$ & $0.83-0.86$ & - & $0.83-0.88$ & $0.85-0.90$ \\
\hline & Bet & $0.82-0.84$ & $0.79-0.83$ & $0.79-0.82$ & $0.79-0.84$ & $0.83-0.88$ \\
\hline \multirow[t]{3}{*}{$2, T_{C J}$} & Val & $0.59-0.62$ & $0.58-0.61$ & - & $0.58-0.62$ & $0.59-0.63$ \\
\hline & AlaOEt & $0.61-0.62$ & $0.58-0.61$ & - & $0.58-0.62$ & $0.59-0.63$ \\
\hline & Bet & $0.64-0.67$ & $0.64-0.65$ & - & $0.64-0.67$ & $0.66-0.69$ \\
\hline \multirow[t]{3}{*}{$2, \mathrm{~T}_{\mathrm{T}}$} & Val & 0.63 & $0.62-0.65$ & $0.61-0.65$ & $0.61-0.65$ & $0.62-0.66$ \\
\hline & AlaOEt & - & $0.61-0.65$ & $0.61-0.65$ & $0.61-0.65$ & $0.62-0.66$ \\
\hline & Bet & $0.68-0.72$ & $0.67-0.70$ & $0.67-0.71$ & $0.67-0.72$ & $0.69-0.74$ \\
\hline \multirow[t]{3}{*}{$3, T_{C J}$} & Val & $0.49-0.51$ & - & - & $0.49-0.51$ & $0.50-0.52$ \\
\hline & AlaOEt & $0.27-0.30$ & - & - & $0.27-0.30$ & $0.31-0.34$ \\
\hline & Bet & $0.43-0.47$ & $0.46-0.47$ & - & $0.43-0.47$ & $0.46-0.50$ \\
\hline \multirow[t]{3}{*}{$3, T_{T}$} & Val & - & - & - & $0.60-0.61^{\dagger}$ & $0.61-0.62^{\dagger}$ \\
\hline & AlaOEt & - & $0.46-0.47$ & $0.45-0.46$ & $0.45-0.47$ & $0.49-0.51$ \\
\hline & Bet & - & - & 0.53 & 0.53 & 0.56 \\
\hline
\end{tabular}

${ }^{\dagger}$ calculation done with $\mu=1.8$

Bet $\cdot \mathrm{Li}^{+}\left(\mathrm{H}_{2} \mathrm{O}\right)$. This result is consistent with previous work which shows that the difference in threshold dissociation energies for loss of water between these nonzwitterionic and zwitterionic isomers for sodiated valine is about $0.05 \mathrm{eV}$ [45]. While small uncertainties exist in the absolute values of $\mathrm{E}_{\mathrm{o}}$ due to uncertainties in parameters that go into the modeling, the relative values should be quite accurate due to both the similar modeling parameters for these isomers and to the nearly identical conditions under which the experimental data was obtained. The overlap in the threshold dissociation energies for loss of water from Val $\cdot \mathrm{Li}^{+}\left(\mathrm{H}_{2} \mathrm{O}\right)$ and AlaOEt$\cdot \mathrm{Li}^{+}\left(\mathrm{H}_{2} \mathrm{O}\right)$ indicates that water is bound similarly in these complexes.

Experimentally determined threshold dissociation energies $\left(E_{o}\right)$ were converted into binding enthalpies $(\Delta \mathrm{H})$ using eq $1[61,65,66]$,

$$
\begin{aligned}
\Delta \mathrm{H}(298 \mathrm{~K}) & =\mathrm{E}_{\mathrm{o}}+\mathrm{E}_{\mathrm{vib}}^{298 \mathrm{~K}}\left(\mathrm{AA} \cdot \mathrm{Li}^{+}+\mathrm{E}_{\mathrm{vib}}^{298 \mathrm{~K}}\left(\mathrm{H}_{2} \mathrm{O}\right)\right. \\
& -\mathrm{E}_{\mathrm{vib}}^{298 \mathrm{~K}}\left(\mathrm{AA} \cdot \mathrm{Li}^{+}\left(\mathrm{H}_{2} \mathrm{O}\right)\right)+4 \mathrm{RT}
\end{aligned}
$$

where $E_{\text {vib }}^{298 K}$ is the average vibrational energy at $298 \mathrm{~K}$. The 4RT term takes into account the six degrees of freedom (three rotational and three translational) formed when the complex dissociates and the $\Delta \mathrm{PV}=$ RT work term that converts energy to enthalpy. These binding enthalpies are given in Table 2. Water binding energies are calculated from lowest-energy structures and these values are given in Table 3. The structures of Bet $\cdot \mathrm{Li}^{+}$and AlaOEt $\cdot \mathrm{Li}^{+}$do not change significantly upon the addition of a single water molecule. The values given in the table for these species are adiabatic binding energies which should be approximately equal

Table 3. Binding energies of water (in eV) for $\mathrm{AA} \cdot \mathrm{Li}^{+}\left(\mathrm{H}_{2} \mathrm{O}\right)_{n}, n=1$ to 3 , from density functional calculations at the $\mathrm{B} 3 \mathrm{LYP} / 6-31++\mathrm{G}^{* *}$ level of theory, with zero-point energy and $\Delta \mathrm{H}(298 \mathrm{~K})$ corrections

\begin{tabular}{llcrrr}
\hline$\left(\mathrm{H}_{2} \mathrm{O}\right)_{n}$ & & Val NZ & Val ZW & AlaOEt & Bet \\
\hline \hline 1 & E (0 K) & 1.12 & $1.00 / 1.12^{\ddagger}$ & 1.10 & 1.08 \\
& ZPE & -0.09 & $-0.08 /-0.09$ & -0.09 & -0.11 \\
H (298K) & -0.09 & $-0.09 /-0.09$ & -0.09 & -0.07 \\
& Total & 0.95 & $0.82 / 0.94^{\ddagger}$ & 0.92 & 0.90 \\
2 & E (0 K) & 0.72 & $0.80 / 0.95^{\ddagger}$ & 0.70 & $0.88 / 0.89^{\ddagger}$ \\
& ZPE & -0.07 & $-0.10 /-0.14$ & -0.07 & $-0.10 /-0.10$ \\
& H (298 K) & -0.09 & $-0.07 /-0.07$ & -0.09 & $-0.07 /-0.08$ \\
& Total & 0.56 & $0.62 / 0.75^{\ddagger}$ & 0.53 & $0.70 / 0.71^{\ddagger}$ \\
3 & E (0 K) & $0.58^{*} / 0.65^{*} / / 0.54^{\dagger} / 0.58^{\dagger \neq}$ & 0.63 & 0.53 \\
& ZPE & $-0.12^{*} /-0.15^{*} / /-0.04^{\dagger} /-0.06^{\dagger}$ & -0.09 & -0.13 & -0.10 \\
& H (298K) & $-0.08^{*} /-0.06^{*} / /-0.12^{\dagger} /-0.11^{\dagger}$ & -0.09 & -0.06 & -0.07 \\
& Total & $0.38^{*} / 0.44^{*} / / 0.38^{\dagger} / 0.41^{\dagger \neq}$ & 0.43 & 0.44 & 0.37 \\
\hline
\end{tabular}

*NO-coordination

†OO-coordination

${ }^{\ddagger}$ Nonadiabatic binding energy 
to the experimentally derived binding energies, i.e., there should not be a significant reverse activation barrier for these reactions. For the nonzwitterion form of valine, the calculated binding energy is an adiabatic value while both adiabatic and nonadiabatic values are given for the zwitterionic form. Isomerization of zwitterionic $\mathrm{Val} \cdot \mathrm{Li}^{+}$to the most stable structure, which is a nonzwitterion, is likely to occur after the transition state of the dissociating complex. This would result in a reverse activation barrier for this reaction which is significant. If this is the case, then the value most comparable to the experiment is the nonadiabatic binding energy. For zwitterionic valine, the difference in nonadiabatic versus adiabatic binding energy is $0.12 \mathrm{eV}$. The absolute values of the calculated binding energies are all greater than the values of the experimentally derived binding energies by $\sim 0.05 \mathrm{eV}$. The agreement in the absolute values obtained by theory and experiment is very good, and theory reproduces the same trend in binding energy obtained from the experimental data. However, theory indicates that no significant difference in water binding energy for the zwitterion and nonzwitterion forms of valine should be measured in this experiment, although the adiabatic binding energies of these two forms of valine differ by $0.13 \mathrm{eV}$.

The Arrhenius plots, threshold dissociation energies, lowest-energy structures, and calculated binding energies all indicate that $\mathrm{Val} \cdot \mathrm{Li}^{+}\left(\mathrm{H}_{2} \mathrm{O}\right)$ is nonzwitterionic, with the lithium ion NO-coordinated and the water molecule interacting entirely with the lithium ion. The addition of a water molecule to $\mathrm{Val} \cdot \mathrm{Li}^{+}$does not change the structure of the amino acid.

\section{$\mathrm{Val} \cdot \mathrm{Li}^{+}\left(\mathrm{H}_{2} \mathrm{O}\right)_{2}$}

The dissociation of water from $\mathrm{Val} \cdot \mathrm{Li}^{+}\left(\mathrm{H}_{2} \mathrm{O}\right)_{2}$ was measured at $\mathrm{T}_{\mathrm{CI}}$ values between $-20-51.2{ }^{\circ} \mathrm{C}\left(-13-51.2{ }^{\circ} \mathrm{C}\right.$ using $\mathrm{T}_{\mathrm{T}}$ ). Below room temperature, there is a discrepancy between the temperature measured using a thermocouple in the cell center and the temperature of the cooled copper jacket. The correlation coefficients for these Arrhenius plots over the range of temperatures selected are $>0.995$ with $\mathrm{T}_{\mathrm{T}}$ and $>0.998$ with $\mathrm{T}_{\mathrm{CJ}}$. Note that slight curvature in the Arrhenius data is expected due to increasing depletion of the higher energy tail of the population at higher temperature $[45,64]$.

To determine the extent of curvature expected, rate constants for $\mathrm{Val} \cdot \mathrm{Li}^{+}\left(\mathrm{H}_{2} \mathrm{O}\right)_{2}$ were calculated as a function of temperature over the temperature range of the experiment using a threshold dissociation energy of $E_{o}$ $=0.62 \mathrm{eV}$. These data are shown in Figure 4, along with the experimentally determined dissociation rate constants for $\mathrm{Val} \cdot \mathrm{Li}^{+}\left(\mathrm{H}_{2} \mathrm{O}\right)_{2}$ using $\mathrm{T}_{\mathrm{T}}$ and $\mathrm{T}_{\mathrm{CJ}}$. The correlation coefficient for the modeled Arrhenius plot using these calculated values is 0.999 . Thus, the extent of curvature that should be present in the data is small and more similar to the experimental data using the uncorrected temperature scale. This suggests that the temperature correction may overestimate the temperature dif-

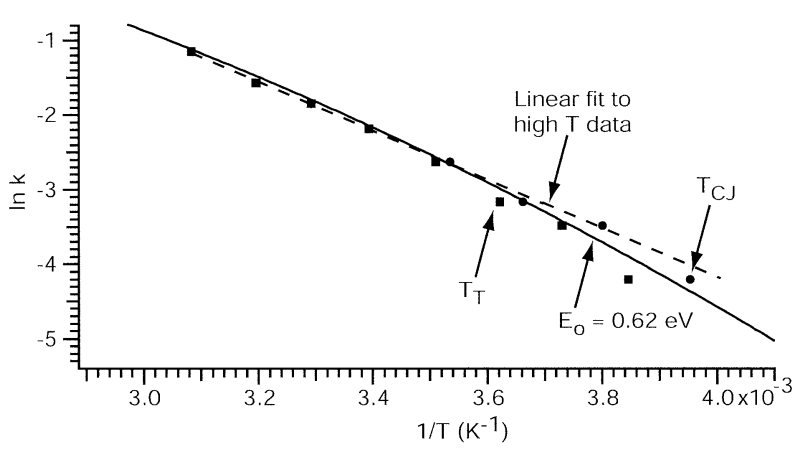

Figure 4. Arrhenius plot for loss of a water molecule from $\mathrm{Val} \cdot \mathrm{Li}^{+}\left(\mathrm{H}_{2} \mathrm{O}\right)_{2}$, with master equation modeled rate constants calculated using a threshold dissociation energy of $\mathrm{E}_{\mathrm{o}}=0.62 \mathrm{eV}$ (solid line), experimentally determined rate constants using the $T_{T}$ temperature scale (squares), and the experimentally determined rate constants using the $\mathrm{T}_{\mathrm{CJ}}$ temperature scale (circles). The dash line is a linear fit to the experimental data measured at temperatures above $22{ }^{\circ} \mathrm{C}$.

ference between the copper jacket and the temperature in the cell center. However, we include results from both scales to get a better measure of the uncertainty in our absolute values.

The Arrhenius plots for $\mathrm{Val} \cdot \mathrm{Li}^{+}\left(\mathrm{H}_{2} \mathrm{O}\right)_{2}$ and AlaOEt $\cdot \mathrm{Li}^{+}\left(\mathrm{H}_{2} \mathrm{O}\right)_{2}$ are quite similar to each other (Figure 1), independent of whether or not the temperature correction is used, and both complexes are different than $\mathrm{Bet}^{-} \mathrm{Li}^{+}\left(\mathrm{H}_{2} \mathrm{O}\right)_{2}$, which suggests similar water binding for the valine and alanine ethyl ester complexes. The measured values of $E_{a}$ and $\log A$ obtained from these Arrhenius data are given in Table 1. Independent of whether the temperature correction is used, these values for $\mathrm{Val} \cdot \mathrm{Li}^{+}\left(\mathrm{H}_{2} \mathrm{O}\right)_{2}$ and AlaOEt$\cdot \mathrm{Li}^{+}\left(\mathrm{H}_{2} \mathrm{O}\right)_{2}$ are identical within error, and less than the $\mathrm{E}_{\mathrm{a}}$ and $\log \mathrm{A}$ for Bet $\cdot \mathrm{Li}^{+}\left(\mathrm{H}_{2} \mathrm{O}\right)_{2}$ by $\sim 25 \%$. These Arrhenius data strongly suggest that the water molecules in $\mathrm{Val} \cdot \mathrm{Li}^{+}\left(\mathrm{H}_{2} \mathrm{O}\right)_{2}$ and AlaOEt $\cdot \mathrm{Li}^{+}\left(\mathrm{H}_{2} \mathrm{O}\right)_{2}$ are bound similarly.

The lowest-energy structures for $\mathrm{AA} \cdot \mathrm{Li}^{+}\left(\mathrm{H}_{2} \mathrm{O}\right)_{2}$ at the B3LYP/6-31+ $+\mathrm{G}^{* *}$ level of theory are shown in Figure 5. AlaOEt $\cdot \mathrm{Li}^{+}\left(\mathrm{H}_{2} \mathrm{O}\right)_{2}$ appears to be a good model for the NO-coordinated valine nonzwitterion, with both water molecules interacting with the lithium ion. Bet $\cdot \mathrm{Li}^{+}\left(\mathrm{H}_{2} \mathrm{O}\right)_{2}$ has the same mode of metal ion and water binding as both the OO-coordinated valine nonzwitterion and zwitterion. Zwitterionic $\mathrm{Val} \cdot \mathrm{Li}^{+}\left(\mathrm{H}_{2} \mathrm{O}\right)_{2}$ is essentially isoenergetic with both lowest-energy nonzwitterionic structures, all of them within $0.06 \mathrm{eV}$ at the B3LYP/6-31++ $\mathrm{G}^{* *}$ level of theory, with zero-point energy and $\Delta \mathrm{H}(298 \mathrm{~K})$ corrections. Theory indicates that all three structures should be present.

Threshold dissociation energies for the loss of water from $\mathrm{AA} \cdot \mathrm{Li}^{+}\left(\mathrm{H}_{2} \mathrm{O}\right)_{2}$ determined from the data using both temperature scales are given in Table 2. Using $\mathrm{T}_{\mathrm{C}}$, the $E_{o}$ values for the valine and alanine ethyl ester complexes are indistinguishable $(0.60 \pm 0.02 \mathrm{eV})$. This value for the betaine complex is distinctly higher ( 0.66 $\pm \quad 0.02 \mathrm{eV})$. Using $\mathrm{T}_{\mathrm{T}}, \quad \mathrm{Val} \cdot \mathrm{Li}^{+}\left(\mathrm{H}_{2} \mathrm{O}\right)_{2}$ and AlaOEt $\cdot \mathrm{Li}^{+}\left(\mathrm{H}_{2} \mathrm{O}\right)_{2}$ have threshold dissociation energies 


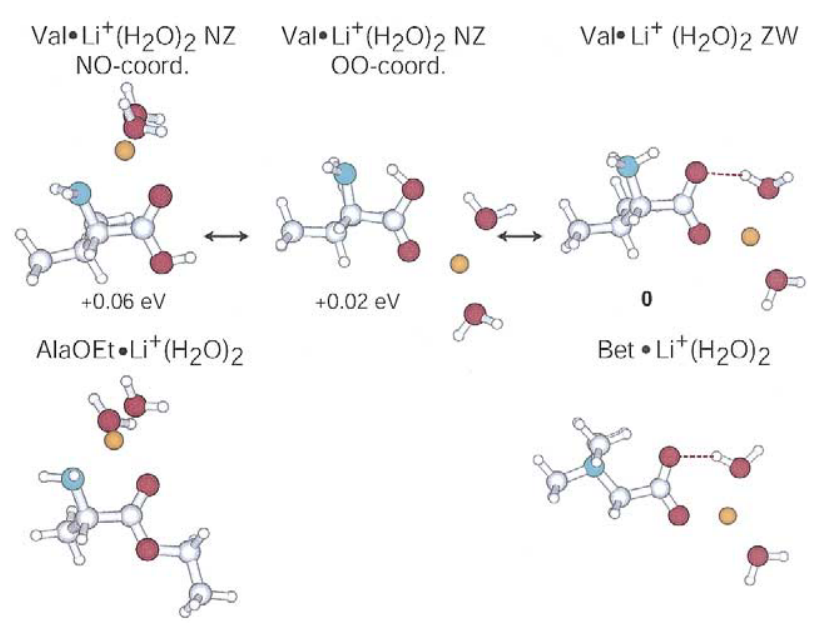

Figure 5. Lowest-energy structures of $\mathrm{AA} \cdot \mathrm{Li}^{+}\left(\mathrm{H}_{2} \mathrm{O}\right)_{2}$ complexes at the B3LYP $/ 6-31++\mathrm{G}^{* *}$ level of theory. Relative energies (in $\mathrm{eV}$ ) include corrections for zero-point energy and enthalpy at $298 \mathrm{~K}$.

of $0.63 \pm 0.02 \mathrm{eV}$, whereas the value for $\mathrm{Bet}^{-\mathrm{Li}^{+}}\left(\mathrm{H}_{2} \mathrm{O}\right)_{2}$ is $0.70 \pm 0.03 \mathrm{eV}$. Thus, using $\mathrm{T}_{\mathrm{T}}$ in the master equation modeling results in $\mathrm{E}_{\mathrm{o}}$ values that are higher by $0.03-$ $0.04 \mathrm{eV}$. However, independent of which temperature scale is used, Bet $\cdot \mathrm{Li}^{+}\left(\mathrm{H}_{2} \mathrm{O}\right)_{2}$ has a threshold dissociation energy that is $\sim 0.06 \mathrm{eV}$ higher than that of both $\mathrm{Val} \cdot \mathrm{Li}^{+}\left(\mathrm{H}_{2} \mathrm{O}\right)_{2}$ and AlaOEt$\cdot \mathrm{Li}^{+}\left(\mathrm{H}_{2} \mathrm{O}\right)_{2}$. The identical values of $E_{o}$ for the valine and alanine ethyl ester complexes indicate that water is bound similarly in these two complexes.

The Arrhenius data and threshold dissociation energies are consistent with a single structure for each of these clusters, although we cannot rule out the presence of rapidly interconverting structures. These data indicate that $\mathrm{Val} \cdot \mathrm{Li}^{+}\left(\mathrm{H}_{2} \mathrm{O}\right)_{2}$ has an NO-coordinated nonzwitterion structure. The addition of two water molecules does not change the structure of $\mathrm{Val} \cdot \mathrm{Li}^{+}$.

Binding energies determined from lowest-energy structures are listed in Table 3. Values which should be comparable to experimental binding enthalpies for betaine and for the zwitterion form of valine are nonadiabatic. These values differ from the adiabatic values by 0.01 and $0.13 \mathrm{eV}$, respectively. In contrast to the results for one water, theory indicates that the zwitterionic form of valine binds the second water molecule $0.19 \mathrm{eV}$ more strongly than the nonzwitterionic form. This difference in energy is nearly the same as that calculated for betaine versus alanine ethyl ester. The ordering of water binding energy is valine zwitterion $\approx$ betaine $>$ valine $\approx$ alanine ethyl ester, in agreement with the ordering from experiment, betaine $>$ valine $\approx$ alanine ethyl ester, assuming that valine is nonzwitterionic. There is good agreement in the absolute values of binding energy determined by experiment and theory.

\section{$A A \cdot \mathrm{Li}^{+}\left(\mathrm{H}_{2} \mathrm{O}\right)_{3}$}

Arrhenius data for the dissociation of water from $\mathrm{AA} \cdot \mathrm{Li}^{+}\left(\mathrm{H}_{2} \mathrm{O}\right)_{3}$ are obtained between -60 and $-20{ }^{\circ} \mathrm{C}$

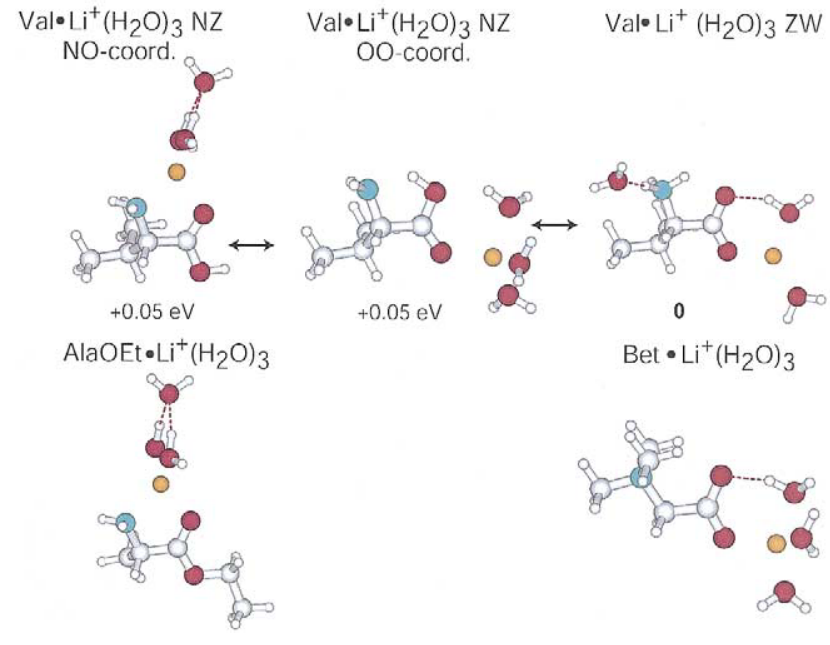

Figure 6. Lowest-energy structures of $\mathrm{AA} \cdot \mathrm{Li}^{+}\left(\mathrm{H}_{2} \mathrm{O}\right)_{3}$ complexes at the B3LYP $/ 6-31++\mathrm{G}^{* *}$ level of theory. Relative energies (in eV) include corrections for zero-point energy and enthalpy at $298 \mathrm{~K}$.

using $\mathrm{T}_{\mathrm{CJ}}\left(-41\right.$ and $-13{ }^{\circ} \mathrm{C}$ using $\left.\mathrm{T}_{\mathrm{T}}\right)$ for the three complexes, and correlation coefficients for these Arrhenius plots (Figure 1) over the range of temperatures selected are $>0.993$ for $\mathrm{T}_{\mathrm{CJ}}\left(>0.992\right.$ for $\left.\mathrm{T}_{\mathrm{T}}\right)$. The measured zero-pressure Arrhenius activation energies and pre-exponential factors obtained from the Arrhenius plots are given in Table 1. The Arrhenius data are clearly different for these compounds, indicating that the third water molecule is bound differently in all three complexes.

Threshold dissociation energies for the loss of the third water molecule of $\mathrm{AA} \cdot \mathrm{Li}^{+}\left(\mathrm{H}_{2} \mathrm{O}\right)_{3}$ are given in Table 2. Using $\mathrm{T}_{\mathrm{CJ}}, \mathrm{E}_{\mathrm{o}}$ for $\mathrm{AA} \cdot \mathrm{Li}^{+}\left(\mathrm{H}_{2} \mathrm{O}\right)_{3}$ is $0.50 \pm 0.01$, $0.29 \pm 0.02$, and $0.45 \pm 0.02 \mathrm{eV}$ for AA $=$ Val, AlaOEt, and Bet, respectively. Using $\mathrm{T}_{\mathrm{T}}$, a value for valine cannot be obtained using our standard parameters in the master equation modeling. A value of $0.61 \mathrm{eV}$ is obtained if the fitting is done using a transition dipole moment multiplication factor of 1.8. This result again indicates that the $\mathrm{T}_{\mathrm{T}}$ scale may overestimate the temperature difference.

Lowest-energy structures for $\mathrm{AA} \cdot \mathrm{Li}^{+}\left(\mathrm{H}_{2} \mathrm{O}\right)_{3}$ at the B3LYP $/ 6-31++\mathrm{G}^{* *}$ level of theory are shown in Figure 6. Including zero-point energy and $\Delta \mathrm{H}(298 \mathrm{~K})$ corrections, zwitterionic $\mathrm{Val} \cdot \mathrm{Li}^{+}\left(\mathrm{H}_{2} \mathrm{O}\right)_{3}$ is $0.05 \mathrm{eV}$ lower in energy than the lowest-energy NO- or OO-coordinated nonzwitterionic structures. AlaOEt $\cdot \mathrm{Li}^{+}\left(\mathrm{H}_{2} \mathrm{O}\right)_{3}$ appears to be a good model for the NO-coordinated Val $\cdot \mathrm{Li}^{+}\left(\mathrm{H}_{2} \mathrm{O}\right)_{3}$ nonzwitterionic form with similar modes of metal ion and water binding. If valine was an NO-coordinated nonzwitterionic complex, the loss of water should be similar to that from AlaOEt $\cdot \mathrm{Li}^{+}\left(\mathrm{H}_{2} \mathrm{O}\right)_{3}$. Clearly this is not the case. Thus, these results indicate that with three water molecules, the mode of water binding is converted from the NO-coordination observed for zero, one, and two water molecules to OO-coordination. With the metal ion OO-coordinated, valine could either be a zwitterion or a nonzwitterion. If 
it was nonzwitterionic, the dissociation kinetics and water binding energy should be similar to that of betaine because the modes of metal ion and water binding are nearly the same. The significantly higher water binding energy for valine versus betaine indicates that valine is a zwitterion, with the third water molecule interacting with the protonated amino group and not with the metal ion. Thus, three water molecules appear to be sufficient to change the mode of metal ion binding from the preferred NO-coordination in the gas phase to OO-coordination, and to turn valine into its zwitterion form that occurs in solution.

The calculated binding energies of water from the lowest-energy structures are given in Table 3 . The values which are comparable to experimental binding enthalpies for the nonzwitterionic forms of valine are nonadiabatic. The calculated binding energies of water for the $\mathrm{Val} \cdot \mathrm{Li}^{+}\left(\mathrm{H}_{2} \mathrm{O}\right)_{3}$ zwitterion and nonzwitterion are essentially the same. The binding energy of water to zwitterionic valine is $0.08 \mathrm{eV}$ below the experimentally derived binding enthalpy. For alanine ethyl ester and betaine, these values differ by $+0.12 \mathrm{eV}$ and $-0.11 \mathrm{eV}$, respectively, using $\mathrm{T}_{\mathrm{CJ}}$. The range of calculated binding energies is $0.07 \mathrm{eV}$, whereas the range of experimental binding enthalpies with $\mathrm{T}_{\mathrm{CJ}}$ is $0.19 \mathrm{eV}$ and with $\mathrm{T}_{\mathrm{T}}$ is $0.12 \mathrm{eV}$. But overall, the agreement in the absolute binding energies between experiment and theory is very good given the relative size of the complexes and the level of theory used.

\section{Conclusions}

Water plays a key role in the structure of amino acids. In bulk solution, amino acids are zwitterionic over a wide range of $\mathrm{pH}$ whereas amino acids are nonzwitterionic in the gas phase. The binding energies of individual water molecules to $\mathrm{Val} \cdot \mathrm{Li}^{+}$complexes with one to three water molecules attached was determined using BIRD. From these values, information about the structures is deduced. Master equation analysis of the experimental data is used to determine threshold dissociation energies using two different temperature scales. The temperature scales correspond to the temperature of the copper shroud surrounding the ion cell and to a thermocouple in the center of the cell. Although the absolute values of the binding energies differ slightly using these two different scales for experiments below room temperature, the relative values for the different isomers with a given extent of hydration do not. We find that the temperature of the copper jacket produces more reliable values based on the range of values required in the master equation modeling and on the extent of curvature in the Arrhenius plots.

Without water, $\mathrm{Val} \cdot \mathrm{Li}^{+}$forms a unique gas-phase structure in which the metal ion is NO coordinated. We find that clusters with one or two water molecules also have the metal ion $\mathrm{NO}$ coordinated and the water molecules interact directly with the lithium ion. Two reference compounds are used as models of nonzwitte- rion and zwitterion structure. The binding energy of water to $\mathrm{Val} \cdot \mathrm{Li}^{+}$is nearly the same as that for the nonzwitterion reference compound for the clusters with one and two water molecules, and these values are different for the zwitterion reference compound. The difference in threshold dissociation energies for the zwitterion versus nonzwitterion model compounds with one and two water molecules is $\sim 0.05 \mathrm{eV}$. This difference is small, but easily measurable in these experiments. There is good agreement between the measured binding energies and the absolute values of binding calculated at the B3LYP/6-31++ $\mathrm{G}^{* *}$ level of theory.

For $\mathrm{Val} \cdot \mathrm{Li}^{+}\left(\mathrm{H}_{2} \mathrm{O}\right)_{3}$, the experimentally determined binding enthalpy of water is greater than that for either of the reference compounds indicating an unusually stable arrangement of water molecules around the amino acid. These results clearly indicate that upon addition of the third water molecule, the position of the metal ion moves from NO coordination, which is observed for zero, one and two water molecules, to $\mathrm{OO}$ coordination. The unique water binding energy for this cluster indicates a salt-bridge form of the cluster in which valine is zwitterionic. Thus, three water molecules are sufficient to form the solution form of valine in these hydrated clusters. Calculations at the B3LYP / 6-31 $++\mathrm{G}^{* *}$ also indicate the zwitterionic form of valine in these clusters is most stable. These results indicate that relatively few water molecules are necessary to produce the solution-phase form of this amino acid.

\section{Acknowledgments}

The authors thank Professor Fred W. McLafferty for his outstanding and innovative contributions in all areas of mass spectrometry, including instrumentation, methods development, theory, both ion and neutral chemistry, applications, and beyond. His pioneering achievements in relating gas-phase ion and neutral chemistry to solution-phase chemistry have provided inspiration for this current work. The authors also gratefully acknowledge financial support provided by the National Science Foundation (grant CHE-0098109). This work was also partially supported by the National Computational Science Alliance under CHE010013N and utilizing the NCSA SGI/CRAY Orgin2000. ASL gratefully acknowledges training support from NIH T32GM08295.

\section{References}

1. Kinnear, B. S.; Kaleta, D. T.; Kohtani, M.; Hudgins, R. R.; Jarrold, M. F. Conformations of Unsolvated Valine-Based Peptides. J. Am. Chem. Soc. 2000, 122, 9243-9256.

2. Kohtani, M.; Jarrold, M. F. The Initial Steps in the Hydration of Unsolvated Peptides: Water Molecule Adsorption on AlanineBased Helices and Globules. J. Am. Chem. Soc. 2002, 124, 11148-11158.

3. Woenckhaus, J.; Hudgins, R. R.; Jarrold, M. F. Hydration of Gas-Phase Proteins: A Special Hydration Site on Gas-Phase BPTI. J. Am. Chem. Soc. 1997, 119, 9586-9587.

4. Mao, Y.; Ratner, M. A.; Jarrold, M. F. One Water Molecule Stiffens a Protein. J. Am. Chem. Soc. 2000, 122, 2950-2951. 
5. Rodriguez-Cruz, S. E.; Klassen, J. S.; Williams, E. R. Hydration of Gas-Phase Gramicidin S $(\mathrm{M}+2 \mathrm{H})^{2+}$ Ions Formed by Electrospray: The Transition from Solution to Gas-Phase Structure. J. Am. Soc. Mass Spectrom. 1997, 8, 565-568.

6. Lee, S. W.; Freivogel, P.; Schindler, T.; Beauchamp, J. L. Freeze-Dried Biomolecules: FT-ICR Studies of the Specific Solvation of Functional Groups and Clathrate Formation Observed by the Slow Evaporation of Water from Hydrated Peptides and Model Compounds in the Gas Phase. J. Am. Chem. Soc. 1998, 120, 11758-11765.

7. Zhan, D.; Fenn, J. B. Gas Phase Hydration of Electrospray Ions from Small Peptides. Int. J. Mass. Spectrom. 2002, 219, 1-10.

8. Vieira, N. E.; Gillian, J. J.; Yergey, A. L. Gas Phase Energetics of the Interactions between Water and Amino Acids. Proceedings of the 51st ASMS Conference on Mass Spectrometry and Allied Topics; Montreal, CN, June 8-12, 2003.

9. Klassen, J. S.; Blades, A. T.; Kebarle, P. Determinations of Ion-Molecule Equilibria Involving Ions Produced by Electrospray. Hydration of Protonated Amines, Diamines, and Some Small Peptides. J. Phys. Chem. 1995, 99, 15509-15517.

10. Liu, D.; Wyttenbach, T.; Barran, P. E.; Bowers, M. T. Sequential Hydration of Small Protonated Peptides. J. Am. Chem. Soc. 2003, 125, 8458-8464.

11. Wyttenbach, T.; Paizs, B.; Barran, P.; Breci, L.; Liu, D.; Suhai, S.; Wysocki, V. H.; Bowers, M. T. The Effect of the Initial Water of Hydration on the Energetics, Structures, and H/D Exchange Mechanism of a Family of Pentapeptides: An Experimental and Theoretical Study. J. Am. Chem. Soc. 2003, 125, 13768-13775.

12. Tschampel, S. M.; Woods, R. J. Quantifying the Role of Water in Protein-Carbohydrate Interactions. J. Phys. Chem. A 2003, 107, 9175-9181.

13. Fye, J. L.; Woenckhaus, J.; Jarrold, M. F. Hydration of Folded and Unfolded Gas-Phase Proteins: Saturation of Cytochrome $c$ and Apomyoglobin. J. Am. Chem. Soc. 1998, 120, 1327-1328.

14. Woenckhaus, J.; Mao, Y.; Jarrold, M. F. Hydration of Gas Phase Proteins: Folded +5 and Unfolded +7 Charge States of Cytochromec. J. Phys. Chem. B 1997, 101, 847-851.

15. Mao, Y.; Ratner, M. A.; Jarrold, M. F. Molecular Dynamics Simulations of the Rehydration of Folded and Unfolded Cytochromec Ions in the Vapor Phase. J. Am. Chem. Soc. 2003, 123, 6503-6507.

16. Rodriguez-Cruz, S. E.; Klassen, J. S.; Williams, E. R. Hydration of Gas-Phase Ions Formed by Electrospray Ionization. J. Am. Soc. Mass Spectrom. 1999, 10, 958-968.

17. Kassab, E.; Langlet, J.; Evleth, E.; Akacem, Y. Theoretical Study of Solvent Effect on Intramolecular Proton Transfer of Glycine. J. Mol. Struc. (Theochem) 2000, 531, 267-282.

18. Price, W. D.; Jockusch, R. A.; Williams, E. R. Is Arginine a Zwitterion in the Gas Phase? J. Am. Chem. Soc. 1997, 119, 11988-11989.

19. Maksic, Z. B.; Kovacevic, B. Neutral Versus Zwitterionic Form of Arginine-An ab Initio Study. J. Chem. Soc., Perkin Trans. 2, 1999, 11, 2623-2629.

20. Rak, J.; Skurski, P.; Simons, J.; Gutowski, M. Low-Energy Tautomers and Conformers of Neutral and Protonated Arginine. J. Am. Chem. Soc. 2001, 123, 11695-11707.

21. Skurski, P.; Gutowski, M.; Barrios, R.; Simons, J. Non-Ionic and Zwitterionic Forms of Neutral Arginine-An ab Initio Study. Chem. Phys. Lett. 2001, 337, 143-150.

22. Chapo, C. J.; Paul, J. B.; Provencal, R. A.; Roth, K.; Saykally, R. J. Is Arginine Zwitterionic or Neutral in the Gas Phase? Results from IR Cavity Ringdown Spectroscopy. J. Am. Chem. Soc. 1998, 120, 12956-12957.

23. Wyttenbach, T.; Witt, M.; Bowers, M. T. On the Question of Salt Bridges of Cationized Amino Acids in the Gas Phase: Glycine and Arginine. Int. J. Mass Spectrom. 1999, 183, 243-252.
24. Hoyau, S.; Ohanessian, G. Interaction of Alkali Metal Cations $\left(\mathrm{Li}^{+}-\mathrm{Cs}^{+}\right)$with Glycine in the Gas Phase: A Theoretical Study. Chem. Eur. J. 1998, 4, 1561-1569.

25. Hoyau, S.; Pelicier, J. P.; Rogalewicz, F.; Hoppilliard, Y.; Ohanessian, G. Complexation of Glycine by Atomic Metal Cations in the Gas Phase. European Journal of Mass Spectrometry 2001, 7, 303-311.

26. Wyttenbach, T.; Witt, M.; Bowers, M. T. On the Stability of Amino Acid Zwitterions in the Gas Phase: The Influence of Derivatization, Proton Affinity, and Alkali Ion Addition. J. Am. Chem. Soc. 2000, 122, 3458-3464.

27. Jensen, F. Glycine Complexes with Metal Ions (Ab Initio). J. Am. Chem. Soc. 1992, 114, 9533-9537.

28. Shoeib, T.; Rodriquez, C. F.; Siu, K. W. M.; Hopkinson, A. C. A Comparison of Copper (I) and Silver (I) Complexes of Glycine, Diglycine and Triglycine. Phys. Chem. Chem. Phys. 2001, 3, 853-861.

29. Ai, H.; Bu, Y.; Han, K. Glycine- $\mathrm{Zn}^{+} / \mathrm{Zn}^{2+}$ and Their Hydrates: On the Number of Water Molecules Necessary to Stabilize the Zwitterionic Glycine- $\mathrm{Zn}^{+} / \mathrm{Zn}^{2+}$ over the Nonzwitterionic Ones. J. Chem. Phys. 2003, 118, 10973-10985.

30. Talley, J. M.; Cerda, B. A.; Ohanessian, G.; Wesdemiotis, C. Alkali Metal Ion Binding to Amino Acids Versus Their Methyl Esters: Affinity Trends and Structural Changes in the Gas Phase. Chem. Eur. J. 2002, 8, 1377-1388.

31. Rodriguez-Santiago, L.; Sodupe, M.; Tortajada, J. Gas-Phase Reactivity of $\mathrm{Ni}^{+}$with Glycine. J. Phys. Chem. A. 2001, 105, 5340-5347.

32. Bertran, J.; Rodriguez-Santiago, L.; Sodupe, M. The Different Nature of Bonding in $\mathrm{Cu}^{+}$-Glycine and $\mathrm{Cu}^{2+}$-Glycine. J. Phys. Chem. B 1999, 103, 2310-2317.

33. Strittmatter, E. F.; Lemoff, A. S.; Williams, E. R. Structure of Cationized Glycine, Gly- $\mathrm{M}^{2+}(\mathrm{M}=\mathrm{Be}, \mathrm{Mg}, \mathrm{Ca}, \mathrm{Sr}, \mathrm{Ba})$, in the Gas Phase: Intrinsic Effect of Cation Size on Zwitterion Stability. J. Phys. Chem. A 2000, 104, 9793-9796.

34. Jockusch, R. A.; Price, W. D.; Williams, E. R. Structure of Cationized Arginine (Arg- $\mathrm{M}^{+}, \mathrm{M}=\mathrm{H}, \mathrm{Li}, \mathrm{Na}, \mathrm{K}, \mathrm{Rb}$, and Cs) in the Gas Phase: Further Evidence for Zwitterionic Arginine. J. Phys. Chem. A 1999, 103, 9266-9274.

35. Skurski, P.; Rak, J.; Simons, J.; Gutowski, M. Quasidegeneracy of Zwitterionic and Canonical Tautomers of Arginine Solvated by an Excess Electron. J. Am. Chem. Soc. 2001, 123, 1107311074.

36. Julian, R. R.; Hodyss, R.; Beauchamp, J. L. Salt Bridge Stabilization of Charged Zwitterionic Arginine Aggregates in the Gas Phase. J. Am. Chem. Soc. 2001, 123, 3577-3583.

37. Julian, R. R.; Beauchamp, J. L.; Goddard, W. A. Cooperative Salt Bridge Stabilization of Gas-Phase Zwitterions in Neutral Arginine Clusters. J. Phys. Chem. A 2002, 106, 32-34.

38. Strittmatter, E. F.; Williams, E. R. Structures of Protonated Arginine Dimer and Bradykinin Investigated by Density Functional Theory: Further Support for Stable Gas-Phase Salt Bridges. J. Phys. Chem. A 2000, 104, 6069-6076.

39. Julian, R. R.; Hodyss, R.; Kinnear, B.; Jarrold, M. F.; Beauchamp, J. L. Nanocrystalline Aggregation of Serine Detected by Electrospray Ionization Mass Spectrometry: Origin of the Stable Homochiral Gas-Phase Serine Octamer. J. Phys. Chem. B 2002, 106, 1219-1228.

40. Schalley, C. A.; Weis, P. Unusually Stable Magic Number Clusters of Serine with a Surprising Preference for Homochirality. Int. J. Mass Spectrom. 2002, 221, 9-19.

41. Cooks, R. G.; Zhang, D. X.; Koch, K. J.; Gozzo, F. C.; Eberlin, M. N. Chiroselective Self-Directed Octamerization of Serine: Implications for Homochirogenesis. Anal. Chem. 2001, 73, 3646-3655.

42. Marino, T.; Russo, N.; Toscano, M. Interaction of $\mathrm{Li}^{+}, \mathrm{Na}^{+}$, and $\mathrm{K}^{+}$with the Proline Amino Acid. Complexation Modes, 
Potential Energy Profiles, and Metal Ion Affinities. J. Phys. Chem B. 2003, 107, 2588-2594.

43. Shoeib, T.; Siu, K. W. M.; Hopkinson, A. C. Silver Ion Binding Energies of Amino Acids: Use of Theory to Assess the Validity of Experimental Silver Ion Basicities Obtained from the Kinetic Method. J. Phys. Chem. A 2002, 106, 6121-6128.

44. Hoyau, S.; Ohannesian, G. Interaction of Proline with $\mathrm{Cu}^{+}$in the Gas Phase. C. R. Acad. Sci. Paris 1998, 1, 795-799.

45. Lemoff, A. S.; Bush, M. F.; Williams, E. R. Binding Energies of Water to Sodiated Valine and Structural Isomers in the Gas Phase: The Effect of Proton Affinity on Zwitterion Stability. J. Am. Chem. Soc. 2003, 125, 13576-13584.

46. Strittmatter, E. F.; Wong, R. L.; Williams, E. R. Effects of Gas-Phase Basicity on the Proton Transfer between Organic Bases and Trifluoroacetic Acid in the Gas Phase: Energetics of Charge Solvation and Salt Bridges. J. Phys. Chem. A 2000, 104, 10271-10279.

47. Strittmatter, E. F.; Williams, E. R. The Role of Proton Affinity, Acidity, and Electrostatics on the Stability of Neutral Versus Ion-Pair Forms of Molecular Dimers. Int. J. Mass Spectrom. 2001, 212, 287-300.

48. Jensen, J. H.; Gordon, M. S. On the Number of WaterMolecules Necessary to Stabilize the Glycine Zwitterion. J. Am. Chem. Soc. 1995, 117, 8159-8170.

49. Yamabe, S.; Ono, N.; Tsuchida, N. Molecular Interactions between Glycine and $\mathrm{H}_{2} \mathrm{O}$ Affording the Zwitterion. J. Phys. Chem. A. 2003, 107, 7915-7922.

50. Balta, B.; Aviyente, V. Solvent Effects on Glycine. I. A Supermolecule Modeling of Tautomerization Via Intramolecular Proton Transfer. J. Comput. Chem. 2003, 24, 1789-1802.

51. Tajkhorshid, E.; Jalkanen, K. J.; Suhai, S. Structure and Vibrational Spectra of the Zwitterion L-Alanine in the Presence of Explicit Water Molecules: A Density Functional Analysis. J. Phys. Chem. B 1998, 102, 5899-5913.

52. Ellzy, M. W.; Jensen, J. O.; Hameka, H. F.; Kay, J. G. Correlation of Structure and Vibrational Spectra of the Zwitterion L-Alanine in the Presence of Water: An Experimental and Density Functional Analysis. Spectrochim. Acta Part A 2003, 59, 2619-2633.

53. Lee, K. T.; Sung, J.; Lee, K. J.; Kim, S. K.; Park, Y. D. Resonant Two-Photon Ionization Study of Jet-Cooled Amino Acid: L-Phenylalanine and Its Monohydrated Complex. J. Chem. Phys. 2002, 116, 8251-8254.

54. Snoek, L. C.; Kroemer, R. T.; Simons, J. P. A Spectroscopic and Computational Exploration of Tryptophan Water Cluster Structures in the Gas Phase. Phys. Chem. Chem. Phys. 2002, 4, $2130-2139$.
55. Xu, S.; Nilles, J. M.; Bowen, K. H., Jr. Zwitterion Formation in Hydrated Amino Acid, Dipole Bound Anions: How Many Water Molecules Are Required? J. Chem. Phys. 2003, 119, 10696-10701.

56. Jockusch, R. A.; Lemoff, A. S.; Williams, E. R. Effect of Metal Ion and Water Coordination on the Structure of a Gas-Phase Amino Acid. J. Am. Chem. Soc. 2001, 123, 12255-12265.

57. Jockusch, R. A.; Lemoff, A. S.; Williams, E. R. Hydration of Valine-Cation Complexes in the Gas Phase: On the Number of Water Molecules Necessary to Form a Zwitterion. J. Phys. Chem. A 2001, 105, 10929-10942.

58. Kushwaha, P. S.; Mishra, P. C. Stability of the Normal, Zwitterionic Neutral and Anionic Forms of Aspartic Acid in Gas Phase and Aqueous Media. J. Mol. Struc. (Theochem) 2001, 549, 229-242.

59. Peteanu, L. A.; Levy, D. H. Spectroscopy of Complexes of Tryptamine and 3-Indolepropionic Acid with Various Solvents. J. Phys. Chem. 1988, 92, 6554-6561.

60. Price, W. D.; Schnier, P. D.; Jockusch, R. A.; Strittmatter, E. F.; Williams, E. R. Unimolecular Reaction Kinetics in the High Pressure Limit without Collisions. J. Am. Chem. Soc. 1996, 118, 10640-10644.

61. Wong, R. L.; Paech, K.; Williams, E. R. Blackbody Infrared Radiative Dissociation at Low Temperature: Hydration of $\mathrm{X}^{2+}\left(\mathrm{H}_{2} \mathrm{O}\right)_{n}$, for $\mathrm{X}=\mathrm{Mg}$, Ca. Int. J. Mass. Spectrom. 2004, 232, $59-66$.

62. Thölmann, D.; Tonner, D. S.; Mcmahon, T. B. Spontaneous Unimolecular Dissociation of Small Cluster Ions, $\left(\mathrm{H}_{3} \mathrm{O}\right)^{+} \mathrm{L}(\mathrm{N})$ and $\mathrm{Cl}^{-}\left(\mathrm{H}_{2} \mathrm{O}\right)(\mathrm{N})(\mathrm{N}=2-4)$, Under Fourier-Transform IonCyclotron Resonance Conditions. J. Phys. Chem. 1994, 98, 2002-2004

63. Schnier, P. D.; Price, W. D.; Jockusch, R. A.; Williams, E. R. Blackbody Infrared Radiative Dissociation of Bradykinin and Its Analogues: Energetics, Dynamics, and Evidence for SaltBridge Structures in the Gas Phase. J. Am. Chem. Soc. 1996, 118, 7178-7189.

64. Price, W. D.; Williams, E. R. Activation of Peptide Ions by Blackbody Radiation: Factors Which Lead To Dissociation in the Rapid Energy Exchange Limit. J. Phys. Chem. A. 1997, 101, $8844-8852$.

65. Jockusch, R. A.; Williams, E. R. Binding Energies of ProtonBound Dimers of Imidazole and N-Acetylalanine Methyl Ester Obtained by Blackbody Infrared Radiative Dissociation. J. Phys. Chem. A 1998, 102, 4543-4550.

66. Dalleska, N. F.; Honma, K.; Armentrout, P. B. Stepwise Solvation Enthalpies of Protonated Water Clusters: CollisionInduced Dissociation as an Alternative to Equilibrium Studies. J. Am. Chem. Soc. 1993, 115, 12125-12130. 